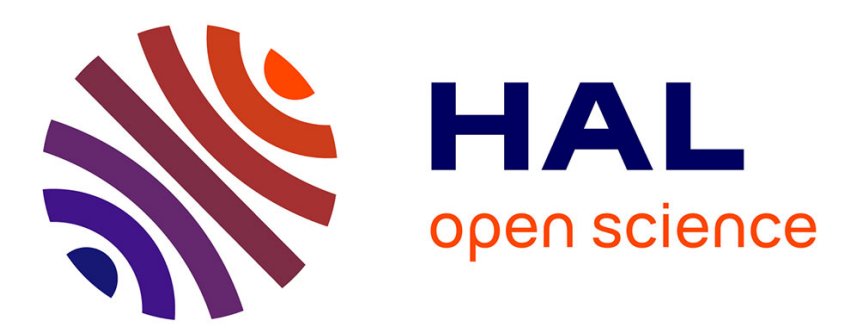

\title{
Recent Developments in Fault Detection and Power Loss Estimation of Electrolytic Capacitors
}

\author{
Ahmed Braham, Amine Lahyani, Pascal Venet, Nejla Rejeb
}

\section{To cite this version:}

Ahmed Braham, Amine Lahyani, Pascal Venet, Nejla Rejeb. Recent Developments in Fault Detection and Power Loss Estimation of Electrolytic Capacitors. IEEE Transactions on Power Electronics, 2010, 25 (1), pp.33 - 43. 10.1109/TPEL.2009.2026749 . hal-00475763

\section{HAL Id: hal-00475763 \\ https://hal.science/hal-00475763}

Submitted on 23 Apr 2010

HAL is a multi-disciplinary open access archive for the deposit and dissemination of scientific research documents, whether they are published or not. The documents may come from teaching and research institutions in France or abroad, or from public or private research centers.
L'archive ouverte pluridisciplinaire HAL, est destinée au dépôt et à la diffusion de documents scientifiques de niveau recherche, publiés ou non, émanant des établissements d'enseignement et de recherche français ou étrangers, des laboratoires publics ou privés. 


\title{
Recent Developments in Fault Detection and Power Loss Estimation of Electrolytic Capacitors
}

\author{
Ahmed Braham, Amine Lahyani, Pascal Venet, and Nejla Rejeb
}

\begin{abstract}
This paper proposes a comparative study of currentcontrolled hysteresis and pulsewidth modulation (PWM) techniques, and their influence upon power loss dissipation in a power-factor controller (PFC) output filtering capacitors. First, theoretical calculation of low-frequency and high-frequency components of the capacitor current is presented in the two cases, as well as the total harmonic distortion of the source current. Second, we prove that the methods already used to determine the capacitor power losses are not accurate because of the capacitor model chosen. In fact, a new electric equivalent scheme of electrolytic capacitors is determined using genetic algorithms. This model, characterized by frequency-independent parameters, redraws with accuracy the capacitor behavior for large frequency and temperature ranges. Thereby, the new capacitor model is integrated into the converter, and then, software simulation is carried out to determine the power losses for both control techniques. Due to this model, the equivalent series resistance (ESR) increase at high frequencies due to the skin effect is taken into account. Finally, for hysteresis and PWM controls, we suggest a method to determine the value of the series resistance and the remaining time to failure, based on the measurement of the output ripple voltage at steady-state and transient-state converter working.
\end{abstract}

Index Terms-Electrolytic capacitors, fault diagnosis, power electronics, power supplies.

\section{NOMENCLATURE}

ESR Equivalent series resistance.

$F_{s} \quad$ Switching frequency.

$I_{0} \quad$ Output current.

PFC Power-factor controller.

$T_{a} \quad$ Ambient temperature.

$T_{c} \quad$ Capacitor case temperature .

$T_{s} \quad$ Switching period.

$T_{v} \quad$ Ageing temperature.

$V_{o \mathrm{DC}} \quad$ Output voltage de value.

$\alpha(t) \quad$ Duty ratio.

$\Delta I \quad$ Half of peak to peak inductor current.

$\Delta V_{o} \quad$ Output voltage ripple.

$\Delta V_{\text {of }} \quad$ Amplitude of $\delta V_{\text {of }}$.

$\Delta V_{\text {op-p }} \quad$ Maximum peak-to-peak value $\delta V_{o}$.

Manuscript received July 31, 2008; revised November 20, 2008, January 30, 2009, and May 12, 2009. Current version published January 29, 2010. Recommended for publication by Associate Editor E. Santi.

A. Braham, A. Lahyani, and N. Rejeb are with the Unite de recherche Matériaux, Mesures et Applications (MMA), Tunis Applied Sciences and Technology National Institute (INSAT), 1080 Tunis, Tunisia (e-mail: ahmed.braham@insat.rnu.tn; amlahyani@yahoo.fr).

P. Venet is with the AMPERE Laboratory UMR Conseil National de la Recherche Scientifique (CNRS) 5005, Université Lyon 1, F-69622, Lyon, France.

Color versions of one or more of the figures in this paper are available online at http://ieeexplore.ieee.org.

Digital Object Identifier 10.1109/TPEL.2009.2026749 $\delta V_{o} \quad$ Output voltage ripple for frequency higher than $200 \mathrm{~Hz}$

$\delta V_{\text {of }} \quad$ Component of $\delta V_{o}$ at the switching frequency. $\delta V_{o L F} \quad$ Output voltage component at $100 \mathrm{~Hz}$.

\section{INTRODUCTION}

$\mathbf{P}$ OWER supplies are essential subsystems of power electronics equipment whose failure lead to the unplanned stopping of the equipment [1]. In power-factor controllers (PFCs), electrolytic capacitors are frequently used for filtering and storage function because of their high capacitance, low size, and cheap price [2], [3]. The capacitors are responsible for most breakdowns of these converters because of their wear out due to the vaporization of electrolyte as a result of the aging time and temperature [4].

Thus, many electrical models of electrolytic capacitors were studied to find a signature of their failure. In the series model, equivalent series resistance (ESR) gives image of power loss inside the capacitor. The increase of ESR is the best indicator of fault for capacitors, and can be deduced from the ripple voltage [5], [6].

However, all the series model components (capacitance, resistance, and inductance) are varying against frequency. As the capacitor current consists of the fundamental frequency and its harmonics, we have to know that the ESR at all these frequencies calculate the power loss for each harmonic, and sum them to obtain the total power loss. For example, in a dc bus of an uninterrupted power supplies with sinusoidal absorption, capacitor manufacturers consider the power loss only at the low frequency and the switching frequency, whereas all other harmonics are neglected [7].

The aim of this study is first to analyze the output capacitor current in order to find theoretical expression of its lowfrequency and high-frequency components for both pulsewidth modulation (PWM) and hysteresis control techniques. Then, we propose a method for the identification of parameters of electrolytic capacitors based on genetic algorithm (GA) [8]. We explain its principle and illustrate some of its potentialities by giving experimental examples. The model obtained by GA is inserted into a boost-type PFC circuit, which commonly represents the first stage of an uninterruptible power supply. A new power loss estimation approach of electrolytic capacitors is described and compared to classic method of power loss calculation.

After this, we show a processing method of the output voltage ripple $\Delta V_{o}$ at the terminals of the capacitor that gives a good image of its series resistance as well as its worn state. The component of $\Delta V_{o}$ that we propose to monitor is $\Delta V_{\text {of }}$, filtered at the switching frequency for PWM control technique and the 


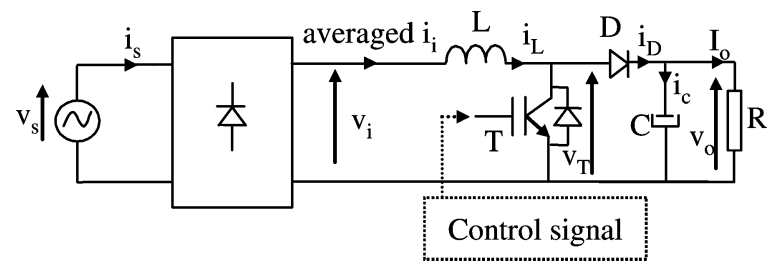

Fig. 1. Boost power-factor-correction circuit.

peak-to-peak value $\Delta V_{\text {op-p }}$ for hysteresis control technique. We also show that these values avoid faulty alarms with frequent load variations. On the other hand, since $\Delta V_{\text {of }}$ and $\Delta V_{\text {op-p }}$ are functions of the series resistance $R_{a}$ of the new capacitor model, the switching frequency (PWM), the current band (hysteresis), the ambient temperature, and the output current, we propose a processing method that is able to estimate the $R_{a}$ value at a given time $t$ by taking into account all these variables, and consequently, the remaining time to failure can be computed online.

\section{PResentation of the Converter And WAVEFORMS ANALYSIS}

Many topologies and control methods of power factor control circuits have been proposed to reduce the harmonic distortion in the line input current and realize the unity power factor. In these PFC circuits, several large electrolytic capacitors are usually used at the output terminal to filter the output voltage. The boost power-factor-correction circuit studied is shown in Fig. 1.

\section{A. Specification of the Converter}

The main characteristics of the converter in hand are as follows.

1) Input ac voltage $V_{i}=230 \mathrm{~V} / 50 \mathrm{~Hz}$.

2) Output voltage $V_{o}$ is equal to $400 V_{\mathrm{DC}}$.

3) Power factor upper than 0.8 .

4) Sinusoidal input current absorption.

5) Peak-current variation $\Delta i_{L}=0.1 \mathrm{~A}$.

6) Nominal switching frequency $F_{s}$ equal to $25 \mathrm{kHz}$.

7) Output voltage ripple $\Delta V_{o}<2 \%$ of $V_{o}$.

8) The total harmonic distortion THD lower than $10 \%$.

9) The nominal load resistance is $80 \Omega$.

10) The power absorbed is less than $2 \mathrm{kVA}$.

\section{B. Inductance Calculation}

At first, the value of the smoothing output inductance should be calculated according to the current ripple $\Delta i_{L}$.

In low frequencies, we have

$$
\left(v_{i}\right)_{\mathrm{LF}}-\left(v_{T}\right)_{\mathrm{LF}}=L \frac{d\left(i_{L}\right)_{\mathrm{LF}}}{d t}=L \omega \frac{d\left(i_{L}\right)_{\mathrm{LF}}}{d \theta}
$$

where $\omega$ is the ac line input voltage pulsation.

When the low-frequency component of the ripple output voltage is neglected, we obtain

$$
\left(v_{T}\right)_{\mathrm{LF}}=(1-\alpha) V_{o}
$$

where $\alpha$ is the duty ratio.
The input voltage $v_{i}$ can be written as

$$
v_{i}=V_{M} \sin (\theta)=V_{M} \sin (\omega t) \quad \text { with } 0 \leq \omega t \leq \pi .
$$

The output power $P_{o}$ is assumed to be almost constant because the output voltage has a very small ripple compared to its dc value. Thus

$$
P_{o}=\frac{V_{M} I_{M}}{2}=V_{o} I_{o}
$$

with $I_{M}$ being the maximum value of the line current.

Substituting (3) and (1) into (2) gives

$\alpha=1-\frac{V_{M}}{V_{o}}\left(\sin \theta-\frac{2 L \omega}{V_{M}^{2}} P_{o} \cos \theta\right) \quad$ with $0 \leq \omega t \leq \pi$.

The inductance $L$ is chosen in such a way that $L \omega I_{M} \ll V_{M}$. The HF component of the ripple current $\Delta i_{L}$ is given by

$$
\left(\Delta i_{L}\right)_{\mathrm{HF}}=\alpha \frac{v_{i}}{2 L} \frac{1}{F_{s}}=\frac{V_{M}}{2 L F_{s}} \sin \theta\left(1-\frac{V_{M}}{V_{o}} \sin \theta\right) .
$$

For PWM, we suppose that the switching frequency $F_{s}$ is fixed, and by derivation of expression (5), the maximum value of the HF ripple current $\left(\Delta i_{L}\right)$ is expressed as follows:

$$
\left(\Delta i_{L \max }\right)=\frac{V_{o}}{8 L F_{s}} .
$$

We have now determined an interval for the inductance value, which is given by

$$
\frac{V_{o}}{8 F_{s}\left(\Delta i_{L \max }\right)} \leq L \ll \frac{V_{M}}{\omega I_{M}} .
$$

Referring to the specification of the converter, $V_{o}=$ $400 \mathrm{~V}, F_{s}=25 \mathrm{kHz}$, and $\left(\Delta i_{L \max }\right)=0.1 \mathrm{~A}$, we now have an inductance, which is $L=0.02 \mathrm{H}$.

For hysteresis control, the switching frequency $F_{s}$ in (5) is variable and its maximum is equal to $25 \mathrm{kHz}$ for $L=0.02 \mathrm{H}$. This gives faster current variations of inductor current $i_{L}$ around its averaged value.

\section{Capacitance Calculation}

The output capacitor is used to filter the output voltage of the PFC. We have to choose the value of $C$ that fulfils the requirement.

Considering that $L \omega I_{M} \ll V_{M}$ and using (4), the duty ratio is expressed as follows:

$$
\alpha=1-\frac{V_{M}}{V_{o}} \sin \theta .
$$

The low-frequency component $\left(i_{D}\right)_{\mathrm{LF}}$ of the current through the diode is written, using the duty ratio, as

$$
\left(i_{D}\right)_{\mathrm{LF}}=(1-\alpha)\left(i_{L}\right)_{\mathrm{LF}}=\frac{2 P_{o}}{V_{o}} \sin ^{2}(\theta) .
$$

On the other hand, the low-frequency component $\left(i_{c}\right)_{\mathrm{LF}}$ of the capacitor current is calculated as

$$
\left(i_{c}\right)_{\mathrm{LF}}=\left(i_{D}\right)_{\mathrm{LF}}-I_{o}=-\frac{P_{o}}{V_{o}} \cos (2 \theta) .
$$




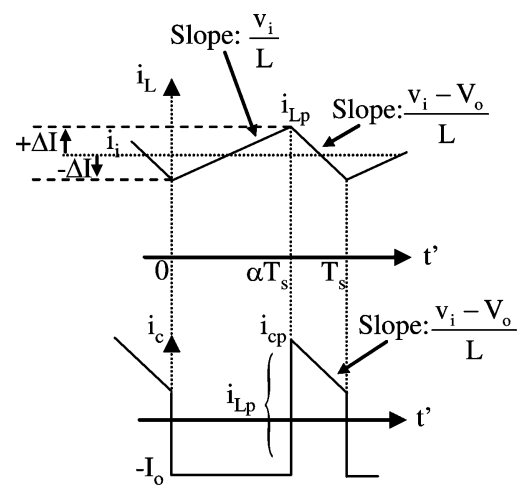

Fig. 2. Waveform of $i_{L}$ and $i_{c}$ at CCM mode.

Then

$$
\left(\Delta V_{o}\right)_{\max }=\frac{P_{o}}{2 C \omega V_{o}} .
$$

According to the PFC specifications, $\Delta V_{o \max } / V_{o} \leq 2 \%$ yields

$$
C>100 \frac{P_{o}}{4 \omega V_{o}^{2}}
$$

We finally chose a capacitor rated $4700 \mu \mathrm{F}, 450 \mathrm{~V}$, and $85^{\circ} \mathrm{C}$.

\section{Capacitor Current Calculation}

A switched-mode power supply can present three possible modes of operation, namely, the continuous conduction mode $(\mathrm{CCM})$, the discontinuous conduction mode (DCM), and the borderline conduction mode (BCM). Kurachi et al. have analyzed the ripple current of the electrolytic capacitor for a boosttype PFC circuit [9]. The authors showed that the capacitor current can be divided into low-frequency and high-frequency components. In our proposed study, we are not interested in the operation modes, but in control methods (PWM and hysteresis).

In order to have an accurate analysis of the ripple current of the electrolytic capacitor $i_{c}$, we suppose that the following hypotheses are true.

1) All elements in the circuit are ideal and have no losses.

2) The input power factor is well controlled to unity value.

3) The switching frequency is much higher than the line input frequency $(50 \mathrm{~Hz})$.

4) The output ripple voltage is negligible compared to the $V_{o \text { DC }}$ value $(400 \mathrm{~V})$.

5) The PFC works at the CCM, as shown in Fig. 2.

For the switching period $T_{s}$, the averaged value $\left\langle i_{c}\right\rangle$ of the instantaneous capacitor current $i_{c}$ is calculated as follows:

$$
\left\langle i_{c}\right\rangle=\alpha(t)\left(-I_{o}\right)+(1-\alpha(t))\left(i_{i}-I_{o}\right)=(1-\alpha(t)) i_{i}-I_{o} .
$$

Referring to (13) and taking into account that $v_{i}=V_{M} \sin (\omega t)$ and $i_{i}=I_{M} \sin (\omega t)$ with $0 \leq \omega t \leq \pi$, we obtain

$$
\left\langle i_{c}\right\rangle=-I_{o} \cos (2 \omega t) .
$$

The low-frequency component $I_{\mathrm{CL}}$ of the capacitor current $i_{c}$ is calculated as

$$
I_{c L}^{2}=\frac{1}{\pi} \int_{0}^{\pi}\left\langle i_{c}\right\rangle^{2} d \theta=\frac{1}{2} I_{o}^{2} .
$$

This formula is valid for both PWM and hysteresis control techniques. On the other hand, the calculation of the high frequency value is different for each control type, as shown later.

1) High-Frequency Component $I_{\mathrm{cH}}$ of the Capacitor Current in PWM Case: Considering that $t^{\prime}$ is a time variable used for analyses during the switching period $T_{s}$, the waveform of the capacitor current $i_{c}$ is expressed as follows.

During the ON state, $t^{\prime} \in\left[0, \alpha(t) T_{s}\right]$ :

$$
i_{c}(t)=-I_{o} .
$$

During the ofF state, $t^{\prime} \in\left[\alpha(t) T_{s}, T_{s}\right]$ :

$$
i_{c}(t)=i_{i}+\frac{v_{i}}{2 L} \alpha(t) T_{s}-I_{o}+\frac{v_{i}-V_{o}}{L}\left(t^{\prime}-\alpha(t) T_{s}\right) .
$$

As shown in (17), the high-frequency component $i_{\mathrm{cH}}$ of the capacitor current $i_{c}$ near the switching frequency is a function of the fixed frequency $F_{s}$ [9]. The square value of $i_{\mathrm{cH}}$ is calculated as follows:

$$
\begin{aligned}
i_{\mathrm{cH}}^{2} & =\frac{1}{T_{s}} \int_{0}^{T_{s}}\left(i_{c}-<i_{c}>\right)^{2} d t^{\prime} \\
& =\frac{v_{i} i_{i}^{2}}{V_{o}}-\frac{v_{i}^{2} i_{i}^{2}}{V_{o}^{2}}+\left(\frac{v_{i}^{3}\left(V_{o}-v_{i}\right)^{2}}{12 L^{2} V_{o}^{3}}\right) \frac{1}{F_{s}^{2}} .
\end{aligned}
$$

Consequently, the total high-frequency component $I_{\mathrm{cH}}$ of the capacitor current $i_{c}$ is written as follows:

$$
\begin{aligned}
I_{\mathrm{cH}}^{2}= & \frac{1}{\pi} \int_{0}^{\pi} i_{\mathrm{cH}}^{2} d \theta=\left[\frac{16 V_{o}}{3 \pi V_{M}}-\frac{3}{2}\right] I_{o}^{2} \\
& +\left[\frac{V_{M}^{3}}{L^{2} V_{o}}\left(\frac{1}{9 \pi}-\frac{V_{M}}{16 V_{o}}+\frac{4 V_{M}^{2}}{45 \pi V_{o}^{2}}\right)\right] \frac{1}{F_{s}^{2}} .
\end{aligned}
$$

2) High-Frequency Component $I_{\mathrm{cH}}$ of the Capacitor Current in Hysteresis Case: During the oN state, $t^{\prime} \in\left[0, \alpha(t) T_{s}\right]$ :

$$
i_{c}(t)=-I_{o} .
$$

During the OFF state, $t^{\prime} \in\left[\alpha(t) T_{s}, T_{s}\right]$ :

$$
i_{c}(t)=i_{i}+\Delta I-I_{o}+\frac{v_{i}-V_{o}}{L}\left(t^{\prime}-\alpha(t) T_{s}\right) .
$$

We note that the relation between $\Delta I$ and $F_{s}$, which is given as follows, is always true:

$$
\Delta I=\frac{v_{i}}{2 L} \alpha(t) T_{s}=\frac{v_{i}}{2 L} \frac{V_{o}-v i}{V_{o}} T_{s} .
$$

For the PWM control, $F_{s}$ is fixed and $\Delta I$ is variable, and in contrast, for hysteresis technique, $\Delta I$ is fixed and $F_{s}$ is variable.

The high-frequency component $i_{\mathrm{cH}}$ of the capacitor current $i_{c}$ near the switching frequency is a function of the fixed 
peak-current variation $\Delta I$, which is given by

$$
\begin{aligned}
i_{\mathrm{cH}}^{2} & =\frac{1}{T_{s}} \int_{0}^{T s}\left(i_{c}-\left\langle i_{c}\right\rangle\right)^{2} d t^{\prime} \\
& =\frac{v_{i} i_{i}^{2}}{V_{o}}-\frac{v_{i}^{2} i_{i}^{2}}{V_{o}^{2}}+\left(\frac{v_{i}}{3 V_{o}}\right) \Delta I^{2} .
\end{aligned}
$$

We get the total high-frequency component $I_{\mathrm{cH}}$ of the capacitor current $i_{c}$ as

$$
\begin{aligned}
I_{\mathrm{cH}}^{2} & =\frac{1}{\pi} \int_{0}^{\pi} i_{\mathrm{cH}}^{2} d \theta \\
& =\left[\frac{16 V_{o}}{3 \pi V_{M}}-\frac{3}{2}\right] I_{o}^{2}+\left[\frac{2 V_{M}}{3 \pi V_{o}}\right] \Delta I^{2} .
\end{aligned}
$$

3) Line Current THD: In order to obtain the same THD in the case of PWM and hysteresis control techniques, the following relation must hold:

$$
\Delta I=\frac{1}{F_{s}}\left[\sqrt{3} \frac{V_{M}}{L V_{o}} \sqrt{\frac{V_{M}^{2}}{32}-\frac{2}{9 \pi} V_{M} V_{o}+\frac{V_{o}^{2}}{24}}\right] .
$$

For our converter specifications, the relation (25) becomes

$$
\Delta I \approx \frac{2000}{F_{s}} .
$$

\section{PARAmeters Determination of Electrolytic CAPACITOR MODEL BY GA}

A sample of aluminum electrolytic capacitors rated $4700 \mu \mathrm{F}, 450 \mathrm{~V}$, and $85^{\circ} \mathrm{C}$ is put in a climate chamber with adjustable temperature. Then the impedance magnitude $|Z|$ and phase measurements are carried out in the laboratory using an HP4284A impedance meter for several temperatures. The capacitor impedance magnitude versus frequency and temperature is shown in Fig. 3.

The electrolytic capacitors can be represented by different electric models [10], [11]. The model selected is subjected to the following two principal constraints for this paper.

1) It must be implemented in any simulation software type.

2) It has to be used in the frequency range of the identified components (dc to several megahertzs).

The selected model is shown in Fig. 4, where its transfer function is given as (27), shown at the bottom of this page.

The main advantages of this model are:

1) a better representation of the electrolytic capacitors technology;

2) the parameters $R_{a}, R_{b}, R_{c}, L$, and $C$ are frequency independent.

Based on a series of measurements, we propose to optimally identify the electrolytic capacitor parameters $R_{a}, R_{b}, R_{c}, L$, and $C$. However, it is important to note that the test measurements are performed with varying factors such as frequencies and temperatures, which would extremely complicate the search

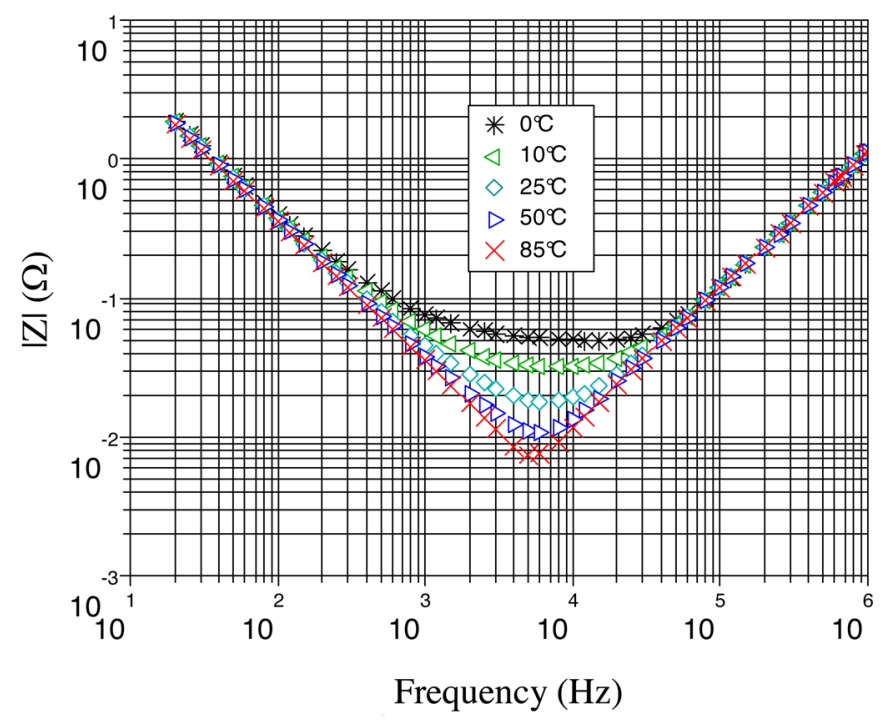

(a)

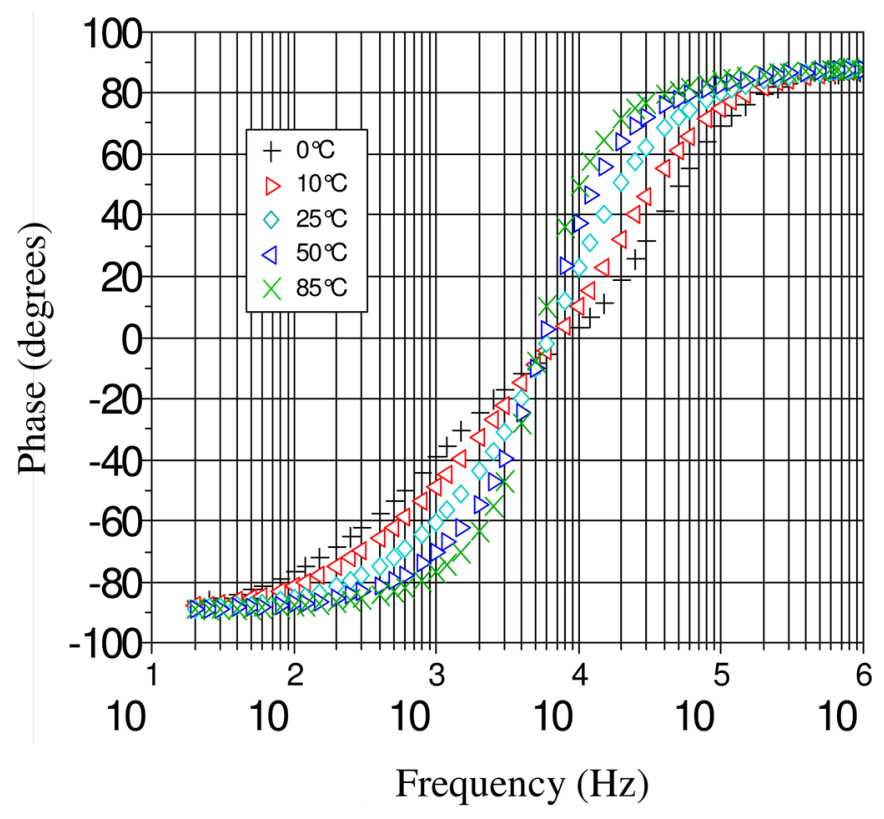

(b)

Fig. 3. Impedance magnitude and phase measurements versus frequency $f$ and temperature T. (a) Magnitude versus $f$ and T. (b) Phase versus $f$ and $T$.

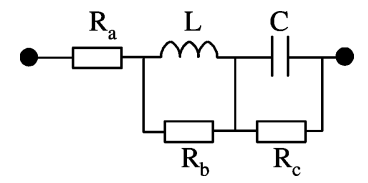

Fig. 4. Electric model of an electrolytic capacitor.

$$
H(p)=\frac{R_{c} L C\left(R_{a}+R_{b}\right) p^{2}+\left(R_{a} R_{b} R_{c} C+L\left(R_{a}+R_{b}+R_{c}\right)\right) p+R_{b}\left(R_{a}+R_{c}\right)}{R_{c} L C p^{2}+\left(R_{b} R_{c} C+L\right) p+R_{b}} .
$$




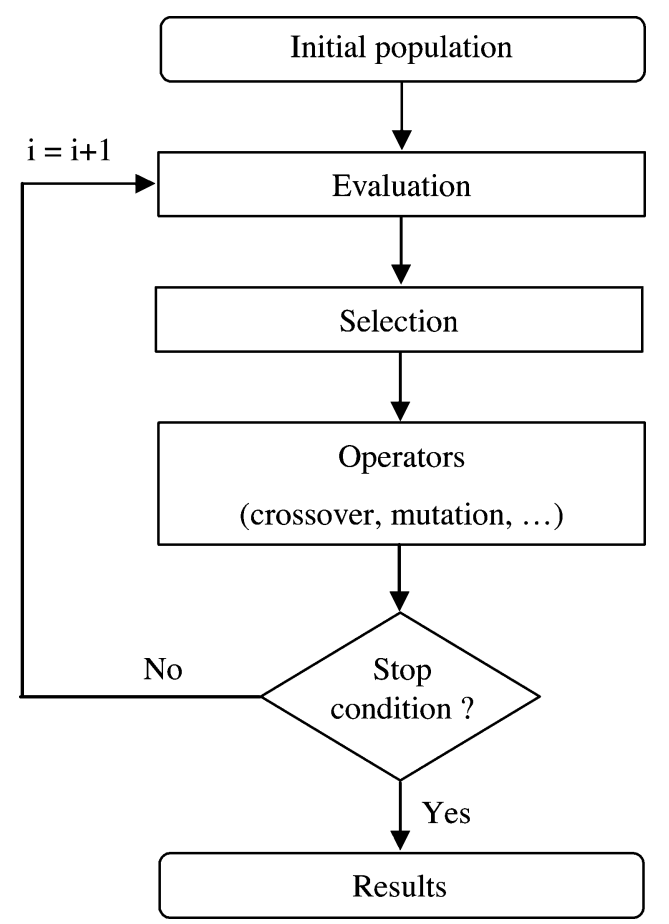

Fig. 5. GA operation.

for an analytic solution of the optimal parameters by resolving partial derivative equations.

Since GA has shown itself capable of evolving solutions in a complex search space, we thought it worthwhile to employ such technique to tune an optimal solution for our parameters. The effectiveness of the proposed technique will be proven in the subsequent development.

In this study, we propose an electric model, taking into account the characteristics variations of the electrolytic capacitors according to the temperature and frequency. The capacitor electrical model parameters are tuned through the use of the GA, which differs from other methods according to the following four points [12], [13].

1) The GA uses a parameters coding and not parameters.

2) The GA performs a random search on a population of points rather than a point.

3) The GA needs neither a priory information on the function to be optimized nor on its derivatives.

4) The GA uses probabilistic rules transitions rather than deterministic ones.

The genetic operations are carried out according to rules of selection, crossover, and mutation. Before achieving a satisfactory result, the algorithm iteration numbers depend on these rules. The GA operations are shown in Fig. 5. The GA affords to find the model parameters starting from the capacitor impedance magnitude and phase measurements according to the frequency.

Optimization is defined by a function minimizing the error between measurement and algorithm calculation. The used cost

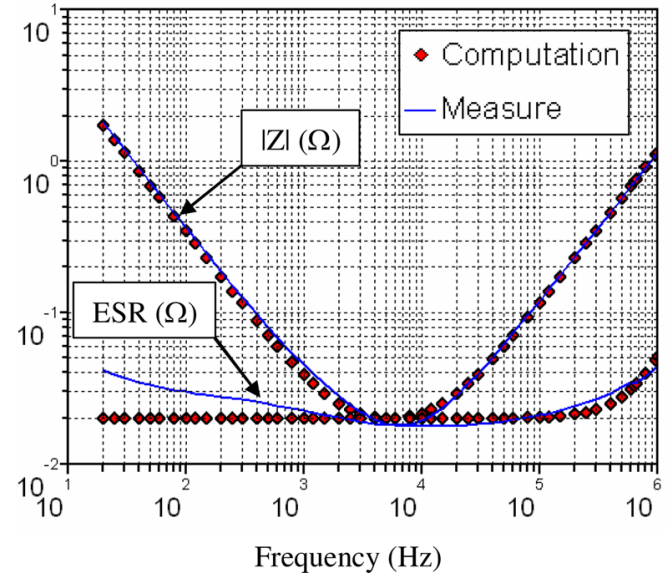

Fig. 6. Identification results at $25^{\circ} \mathrm{C}$.

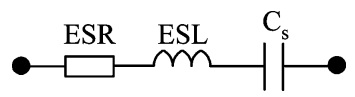

Fig. 7. Series equivalent circuit.

function $\left(J_{\min }\right)$ is given by the following expression:

$$
J_{\text {min }}=\frac{1}{2} \sum\left(\log |Z|_{\text {measures }}-\log |Z|_{\text {computation }}\right)^{2} \text {. }
$$

Fig. 6 shows the parameters identification results for the precedent model for a temperature of $25^{\circ} \mathrm{C}$.

We emphasize that the GA developed for the identification is integrated into the SCilab software. We note that at low frequencies, there is a difference between the estimated and the measured ESR due to the low convergence of the GA. However, the obtained mean error between measures and computation is less than $0.1 \%$ for each temperature. Thus, the identification results are quite satisfactory.

\section{POWER LOSS ESTIMATION}

An electric equivalent scheme of an electrolytic capacitor, as shown in Fig. 7, can be described as an ESR, an equivalent series inductance (ESL), and a capacitance $C_{s}$.

The current trough the capacitor will cause a power loss $\left(P_{\mathrm{LOSS}}\right)$ in it due to the ESR. On the one hand, ESR decreases with increasing temperature and rises at high frequencies. On the other hand, the current consists of main frequency and its harmonics; we calculate the power loss for each harmonic and sum them to obtain the total power loss in the capacitor

$$
P_{\mathrm{LOSS}}=\sum_{k=1}^{n} P_{k}=\sum_{k=1}^{n} \operatorname{ESR}_{(k)} I_{(k)}^{2} .
$$

To calculate $P_{\text {LOSS }}$ precisely, you should know for each harmonic $k$, the corresponding values of the resistance $\operatorname{ESR}_{(k)}$ and the current $I_{(k)}$. At applications with large frequency bandwidth of capacitor current, this makes the power loss calculations difficult to perform, especially if the ESR depends highly on the frequency. Generally, the power dissipation $P_{\mathrm{LOSS}}$ in the electrolytic capacitor is expressed by most capacitor manufacturers 


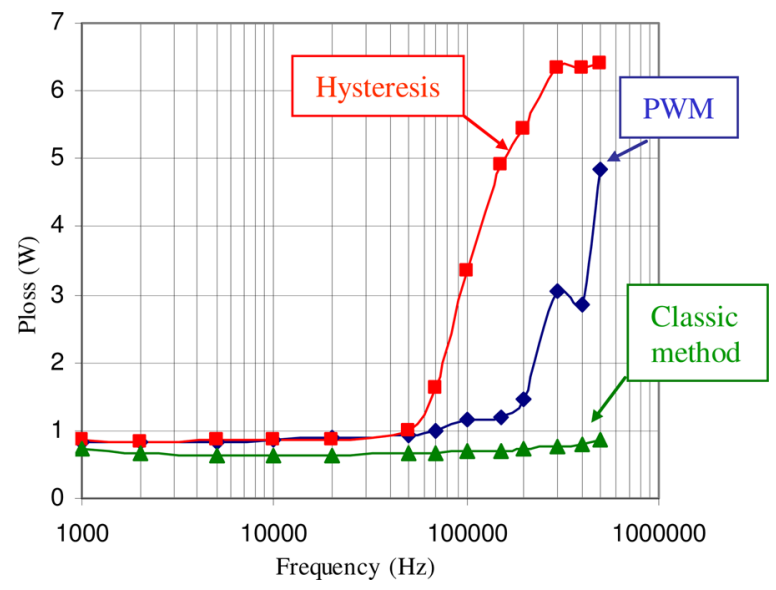

Fig. 8. Power loss simulation versus frequency for $I_{o}=5 \mathrm{~A}$ and $T_{a}=25^{\circ} \mathrm{C}$.

as follows:

$$
P_{\mathrm{LOSS}}=\mathrm{ESR}_{L} I_{\mathrm{cL}}^{2}+\mathrm{ESR}_{H} I_{\mathrm{cH}}^{2}
$$

where

$\mathrm{ESR}_{L} \quad$ is the ESR value at low frequency $(100 \mathrm{~Hz})$;

$\mathrm{ESR}_{H}$ is the ESR value in the high-frequency region;

$I_{\mathrm{CL}} \quad$ is the rms current value at $100 \mathrm{~Hz}$;

$I_{\mathrm{cH}} \quad$ is the rms current value in the high-frequency region.

Using the electrical model obtained by GA (Fig. 4), we propose a new power loss calculation approach. We have to simply determine the current values through the resistances $R_{a}, R_{b}$, and $R_{c}$. The power loss is given by

$$
P_{\mathrm{LOSS}}=R_{a} I_{a}^{2}+R_{b} I_{b}^{2}+R_{c} I_{c}^{2}
$$

where $R_{a}, R_{b}$, and $R_{c}$ are the resistances of the model of Fig. 4, which are independent from frequency, and $I_{a}, I_{b}$, and $I_{c}$ are, respectively, the rms values of the currents across $R_{a}, R_{b}$, and $R_{c}$.

The identification of $R_{a}, R_{b}$, and $R_{c}$ by GA and the determination of $I_{a}, I_{b}$, and $I_{c}$ using the PSIM Software afford efficiency and accuracy to power loss calculation. Fig. 8 shows the power loss variation versus switching frequency from 1 to $500 \mathrm{kHz}$ computed by three different methods. The classic method is obtained using (30). The second curve is carried out using (31) with PWM control. The third curve uses (30) with current-controlled hysteresis modulation corresponding to a peak-current variation $\Delta I$ holding (26). By verifying this latter equation, the currentcontrolled hysteresis modulation gives the same line THD as PWM.

First, we note a significant difference between $P_{\text {LOSS }}$ calculated using the classic method and the new model (PWM and hysteresis control). According to our analysis, we explain that results differ due to the following reasons.

1) The classic method does not take into account the power dissipation due to other capacitor current harmonics.

2) It supposes that the ESR value remain constant for frequency higher than $100 \mathrm{kHz}$.

Moreover, the ESR increases at high frequencies because of the skin effect. In fact, the power dissipation in the resistance $R_{b}$ (see Fig. 4) increases, which also makes the total $P_{\text {LOSS }}$ rise.
On the other hand, we also observe that the hysteresis control causes much power dissipation compared to PWM, mainly for high frequencies and tight peak-current variation. This comparison is legitimated since we suppose that the line current THD is maintained the same for both control techniques by holding (26). We can explain this difference by the spreading spectrum of the capacitor current in the hysteresis case, which involves higher power dissipation than PWM case due to the high-frequency components of the current. Moreover, this difference is accentuated at high frequencies because of the increase in ESR, which is caused by the skin effect. For capacitor manufacturers and PFC users, the curve illustrated by Fig. 8 is very useful since it can be determined for any ambient temperature. In fact, if we fix the hotspot temperature and know the thermal resistance between the hotspot of the capacitor and the ambient, we can determine the maximum allowed power dissipation, and also the maximum switching frequency $F_{s}$ (for PWM) and peak current $\Delta I$ (for hysteresis control).

\section{Fault-Detection Method of Electrolytic Capacitor}

The deterioration of electrolytic capacitor is characterized by a drift of its electric parameters. The ESR increases and the capacitance $C$ decreases [1]. The ESR rise is very interesting because its evolution versus temperature and ageing time follows a well-known function. The main component of ESR is the resistance $R_{a}$, shown by the new model of Fig. 4 . In fact, the study [10] showed that the variation $R_{c}$ resistance representing the leakage current is not very significant during the capacitor wear out. Also, the inductance $L$ and the resistance $R_{b}$ can be considered as constant and does not have a great influence. It was shown that the resistance $R_{a}$ is the best fault indicator since it varies against ageing time and temperature according to the law [10]

$$
R_{a}(t)=d_{1}+d_{2} \exp \left(d_{3} t\right)
$$

where $d_{1}, d_{2}$, and $d_{3}$ are coefficients depending on the capacitor type and temperature, and $t$ is given by Arrhenius law [1]

$$
\frac{t}{t_{v}}=\exp \left[4700 \frac{T v-T}{(T v+273)(T+273)}\right]
$$

with $t_{v}$ being the ageing time corresponding to the accelerated ageing temperature $T_{v}$ and $t$ is the time corresponding to the temperature $T$. Now, the problem is to find which electrical waveform of the PFC gives a good image of the resistance $R_{a}$. We represent the line current $i_{s}$ and the output voltage $V_{o}$ obtained by PSIM software simulation for a sound filtering capacitor in Fig. 9.

We noted that when $R_{a}$ increases against output capacitor wear out, the output voltage ripple rises according to $R_{a}$. Actually, we must know which component of that voltage we should monitor to have a faithful image of $R_{a}$ at steady state working of the converter as well as at variable load functioning.

Let us consider the output voltage as a sum of three components as follows:

$$
V_{o}=V_{o \mathrm{DC}}+\Delta V_{o}=V_{o \mathrm{DC}}+\delta V_{o \mathrm{BF}}+\delta V_{o}
$$




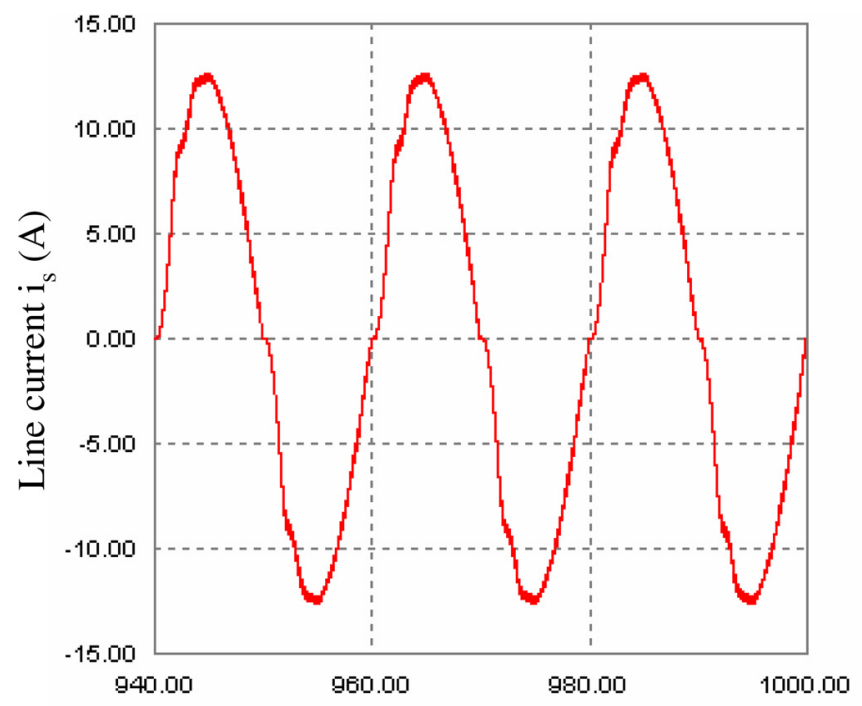

Time (ms)

(a)

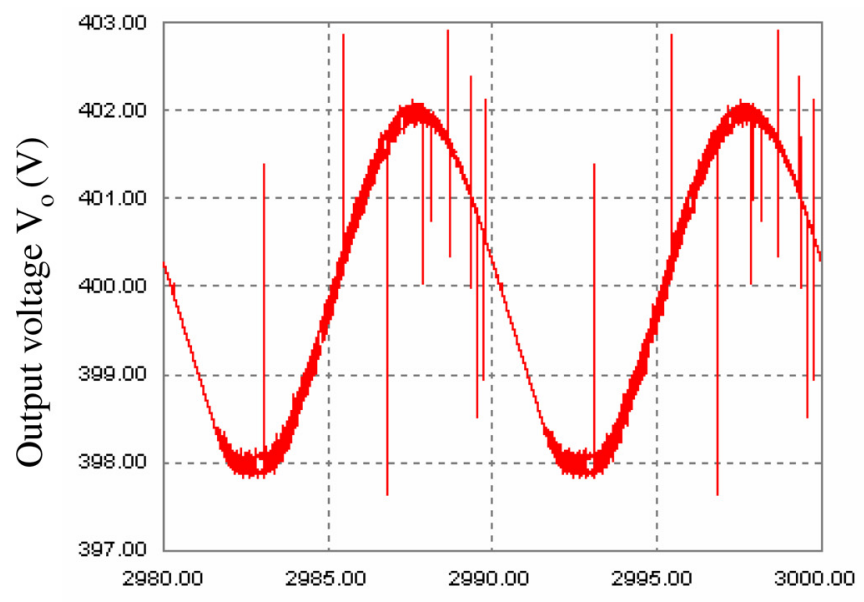

Time (ms)

(b)

Fig. 9. Line current and output voltage simulation for sound capacitor and $I_{o}$ $=5$ A. (a) Line current $i_{s}$. (b) Output voltage $V_{o}$.

where

$V_{o \mathrm{DC}} \quad$ output $400 \mathrm{~V} / \mathrm{dc}$ voltage;

$\delta V_{o \mathrm{BF}}$ component of $V_{o}$ at $100 \mathrm{~Hz}$ (double-line pulse);

$\delta V_{o} \quad$ is composed of the $100 \mathrm{~Hz}$ multiples, the switching frequency $F_{s}$, and its multiples.

In the following study, we propose a method to choose the best waveform that reflects the $R_{a}$ value and also the capacitor wear-out state.

\section{A. PWM Control Case}

In this case, we suggest to monitor the $\delta V_{o}$ component at the switching frequency denoted by $\delta V_{\text {of }}$. Indeed, for the PWM, the frequency spectrum of the capacitor current and the output voltage is distinct, as shown in Fig. 10.

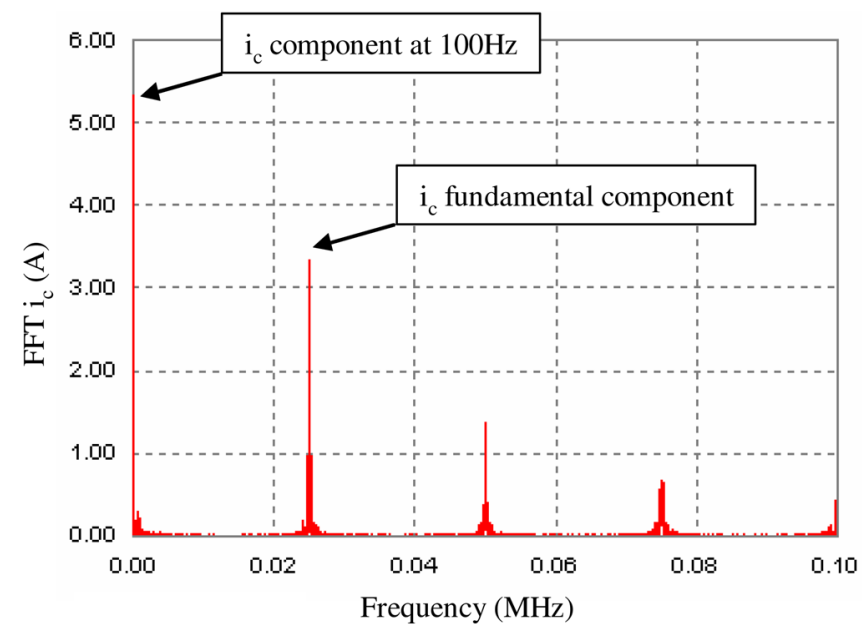

(a)

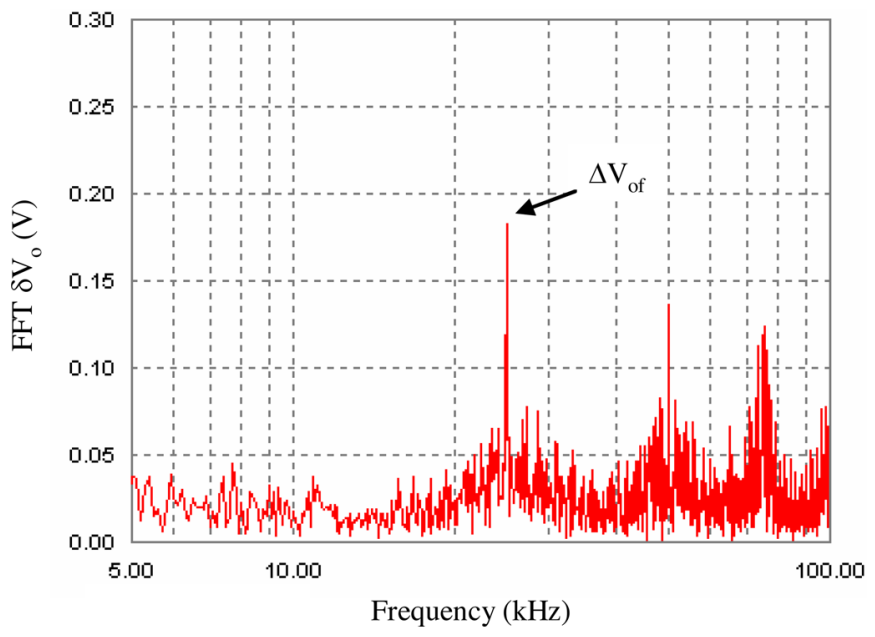

(b)

Fig. 10. FFT of $i_{c}$ and $\delta V_{o}$ for $I_{o}=5 \mathrm{~A}$ and $F_{s}=25 \mathrm{kHz}$ for sound capacitors. (a) Capacitor current spectrum. (b) Output voltage spectrum.

By using a bandpass filter centered at the switching frequency $F_{s}$, the amplitude $\Delta V_{\text {of }}$ of $\delta V_{\text {of }}$ can be extracted and monitored. Yet, the relation between the resistance $R_{a}$ and $\Delta V_{\text {of }}$ is expressed as follows:

$$
\Delta V_{\text {of }}=\left|\overline{Z_{c}}\right| \times I_{\mathrm{cf}}
$$

where

$\left|\overline{Z_{c}}\right|$ is the magnitude of the capacitor impedance. It is a function of $R_{a}, F_{s}$, and the ambient temperature $T_{a}$, so it can be written as $f\left(T_{a}, R_{a}, F_{s}\right)$.

$I_{\mathrm{cf}} \quad$ is the amplitude of the $i_{c}$ fundamental component. It is expressed as a function $g\left(I_{o}, F_{s}\right)$.

Then, we have

$$
\Delta V_{\text {of }}=f\left(T_{a}, R_{a}, F_{s}\right) \times g\left(I_{o}, F_{s}\right) .
$$

Finally, we obtain

$$
\Delta V_{\text {of }}=h\left(T_{a}, R_{a}, F_{s}, I_{o}\right) .
$$

First, we suppose that $R_{a}$ and $T_{a}$ are constants $\left(R_{a}=19 \mathrm{~m} \Omega\right.$ and $T_{a}=25{ }^{\circ} \mathrm{C}$ at the capacitor sound state), and in Fig. 11, 


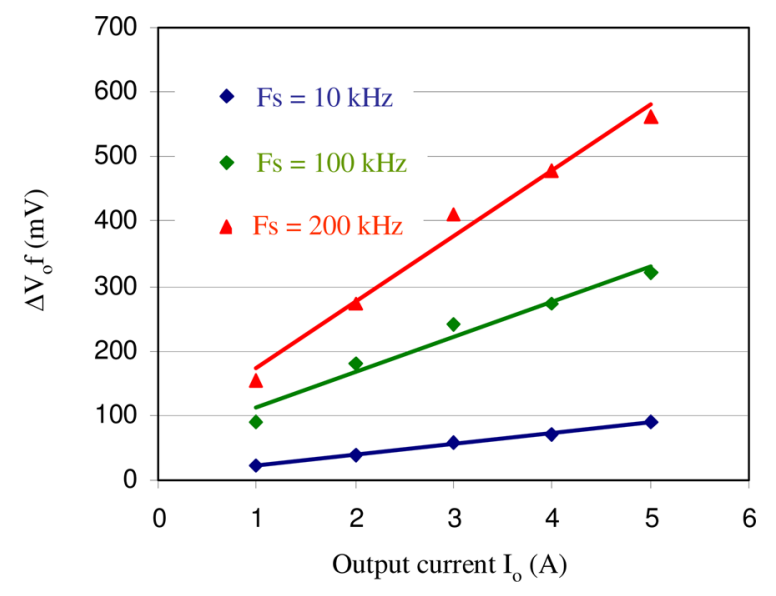

Fig. 11. Simulation of $\Delta V_{\text {of }}$ versus $I_{o}$ and $F_{s}$ for $R_{a}=19 \mathrm{~m} \Omega$ and $T_{a}=$ $25^{\circ} \mathrm{C}$.

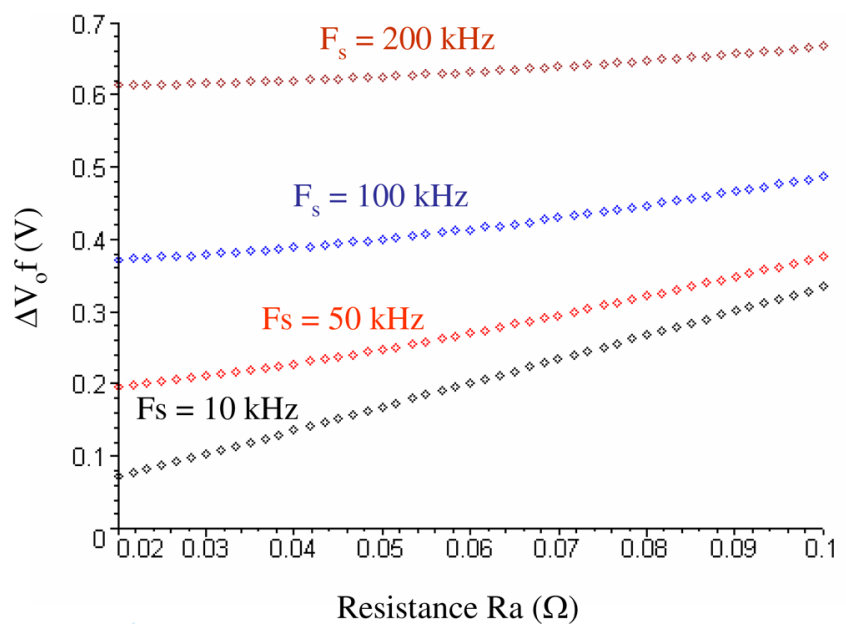

Fig. 12. Simulation of $\Delta V_{\text {of }}$ versus $R_{a}$ and $F_{s}$ for $I_{o}=5 \mathrm{~A}$ and $T_{a}=$ $25^{\circ} \mathrm{C}$.

we represent the variation of $\Delta V_{\text {of }}$ versus the output current $I_{o}$ and the switching frequency $F_{s}$ obtained by PSIM software simulation. We observe that the curves are approximately linear against $I_{o}$ for each frequency.

Then, by using MAPLE software, in Fig. 12, we represent the variation of $\Delta V_{\text {of }}$ versus $R_{a}$ and for different frequencies $F_{s}$. $R_{a}$ ranges from 19 (capacitors sound state) to $100 \mathrm{~m} \Omega$ (capacitor supposed at worn state). We obtain almost linear curves with a slope that decreases when the switching frequency increases.

Then, we conclude that at steady-state operation of the PFC, the component of output voltage ripple at the switching frequency $\Delta V_{\text {of }}$ gives a good image of the resistance $R_{a}$. The function $h$ can be determined for discrete points of $I_{o}, T_{a}, F_{s}$, and $R_{a}$, and then stored in a database for online processing of the capacitor resistance $R_{a}$.

Now, let us suppose that the PFC is driven to a sudden load variation at time $t=2 \mathrm{~s}$ from $I_{o}=1 \mathrm{~A}$ to $I_{o}=5 \mathrm{~A}$. The output voltage $V_{o}$ and the line current $i_{s}$ present a transient state, as shown in Fig. 13.

Compared to the averaged rectified signal that can be used in such cases and may give faulty alarms [5], the amplitude $\Delta V_{\text {of }}$ of the output voltage $V_{o}$ at the switching frequency that we propose

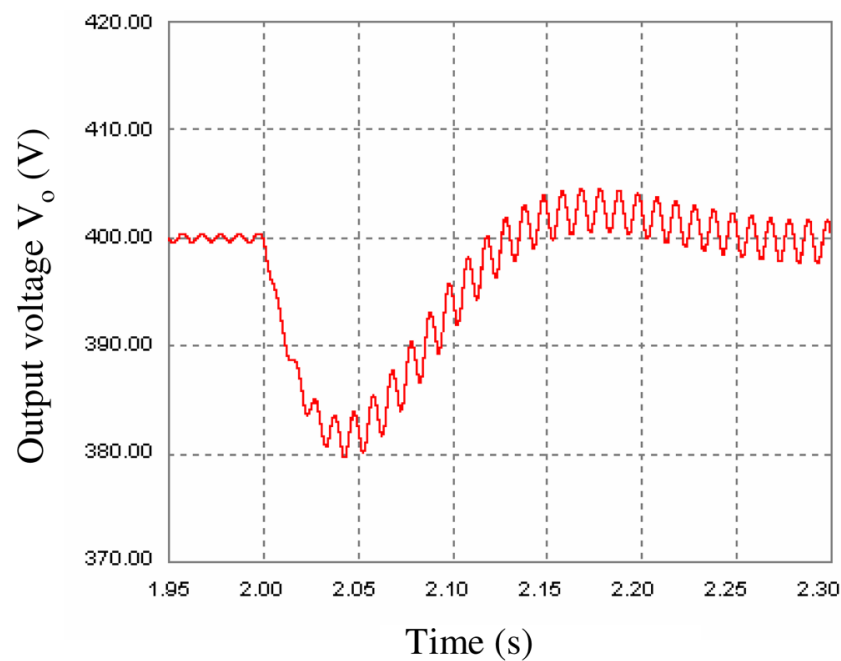

(a)

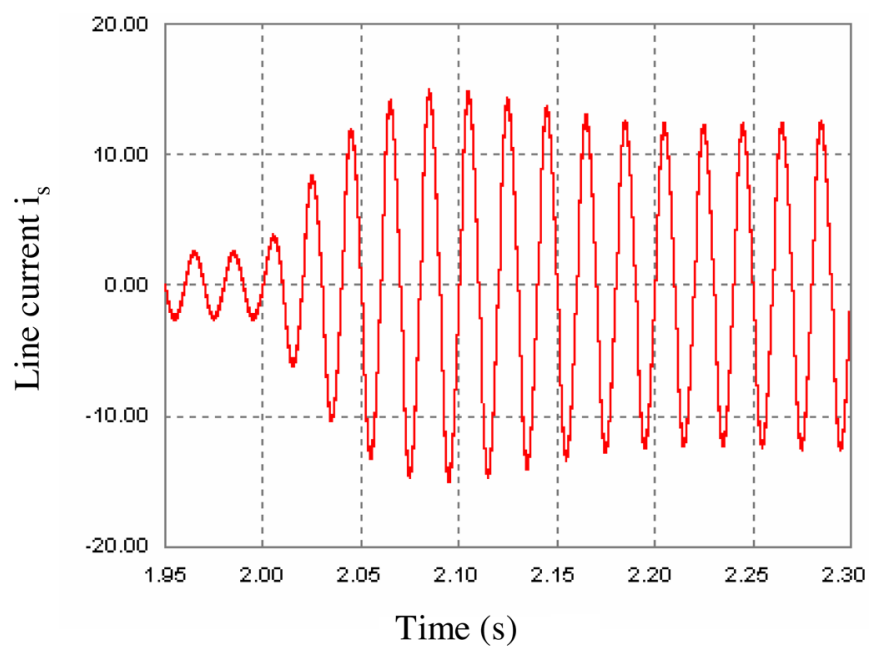

(b)

Fig. 13. Simulation of the influence of a variable load from $I_{o}=1$ A to $I_{o}$ $=5 \mathrm{~A}$ on PFC waveforms. (a) Transient output voltage $V_{o}$. (b) Transient line current.

to monitor is confirmed to be a better image of the resistance $R_{a}$, since it is not influenced by the load variation and avoids errors in $R_{a}$ determination. Fig. 14 shows the variation of $\delta V_{\text {of }}$ during the load variation state and confirms that its amplitude is not very affected by this transient state.

\section{B. Current-Controlled Hysteresis Case}

In this case, we propose to monitor the peak-to-peak value of $\delta V_{o}$ component at the switching frequency denoted by $\Delta V_{\text {op-p }}$. Indeed, for the hysteresis control technique, the frequency spectrum of the capacitor current is very irregular and its components are distributed along the frequency range except the component at $100 \mathrm{~Hz}$, which is distinct (see Fig. 15).

We have remarked that the peak-to-peak value $\Delta V_{\text {op-p }}$ increases against the resistance $R_{a}$. Its value can be measured practically by associating a high-pass filter with a band-stop filter centered at $100 \mathrm{~Hz}$ to the output voltage $V_{o}$ at the terminals of the capacitor. We obtain by PSIM simulation, the waveform shown in Fig. 16. 


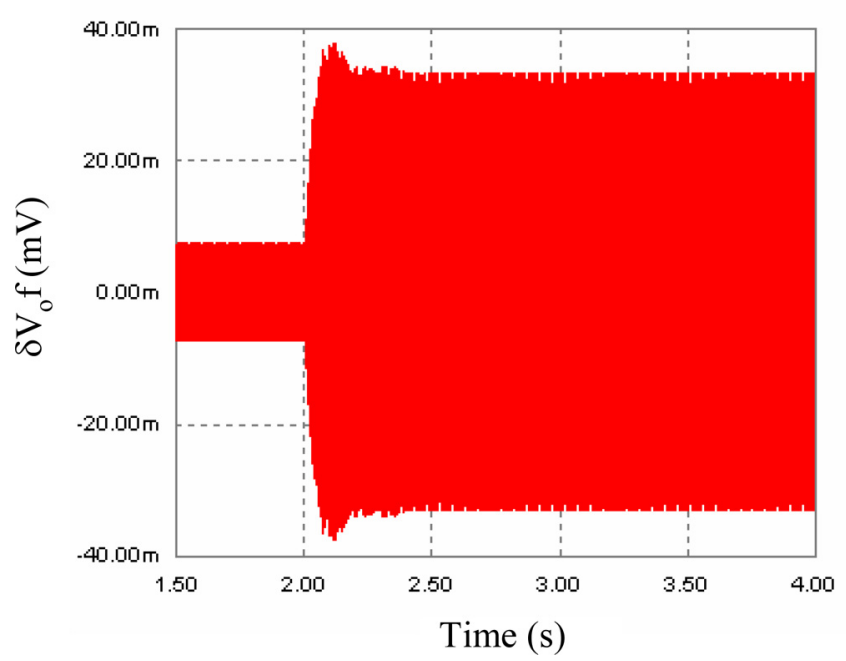

Fig. 14. Simulation of $\delta V_{\text {of }}$ during load variation state from $I_{o}=1 \mathrm{~A}$ to $I_{o}=5 \mathrm{~A}$.

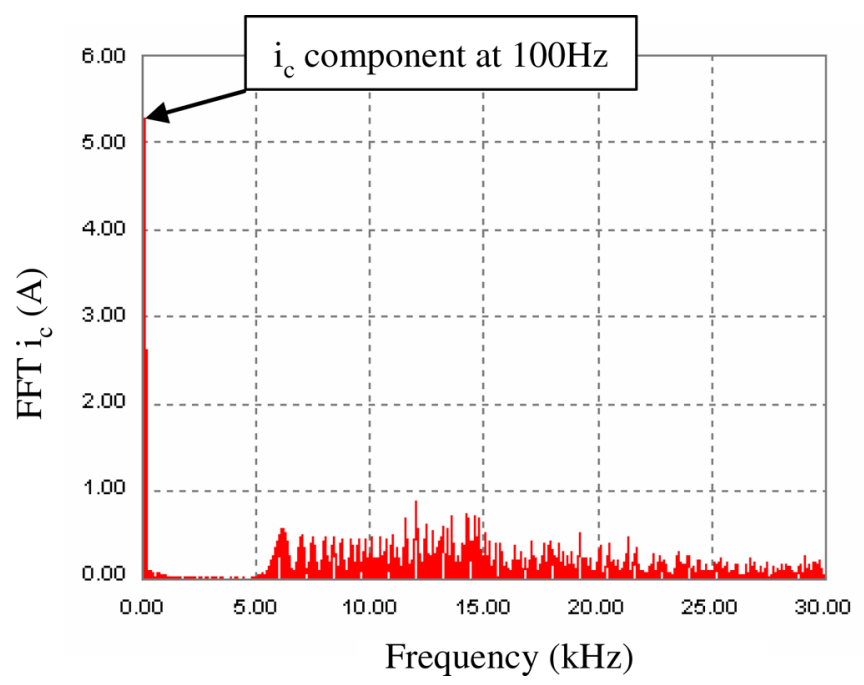

Fig. 15. Capacitor current spectrum for $I_{0}=5 \mathrm{~A}$.

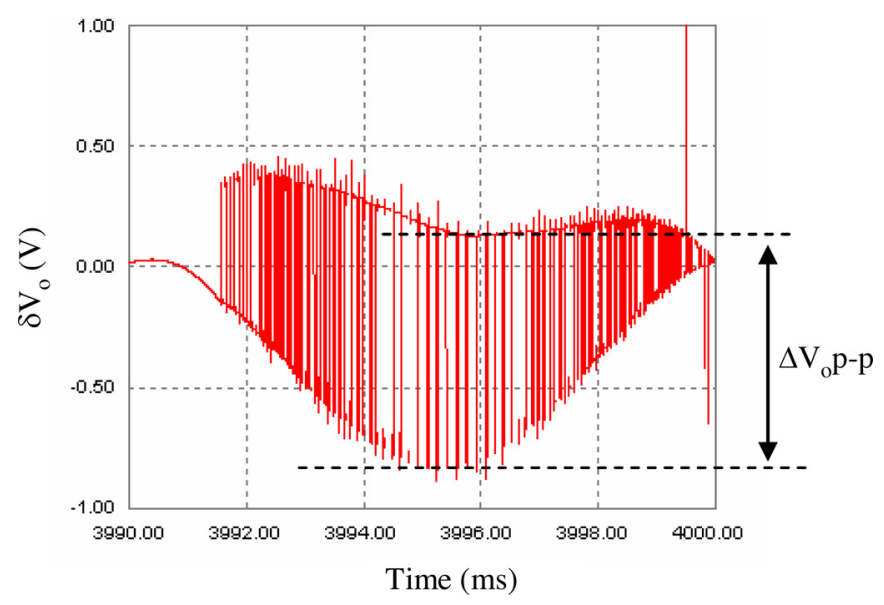

Fig. 16. $\delta V_{o}$ versus time for $I_{o}=5 \mathrm{~A}$ and $\Delta I=0.1 \mathrm{~A}$.

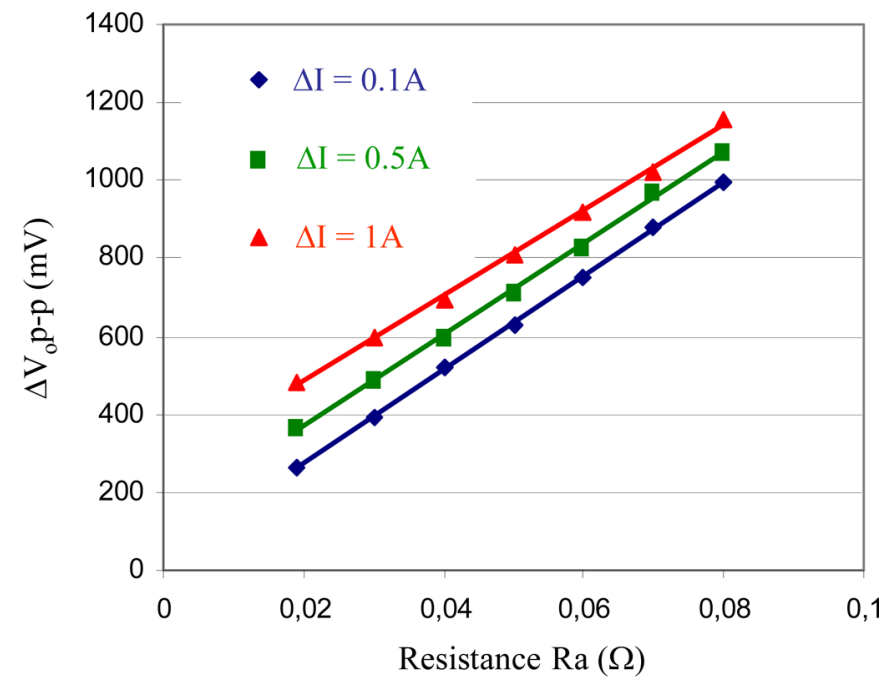

(a)

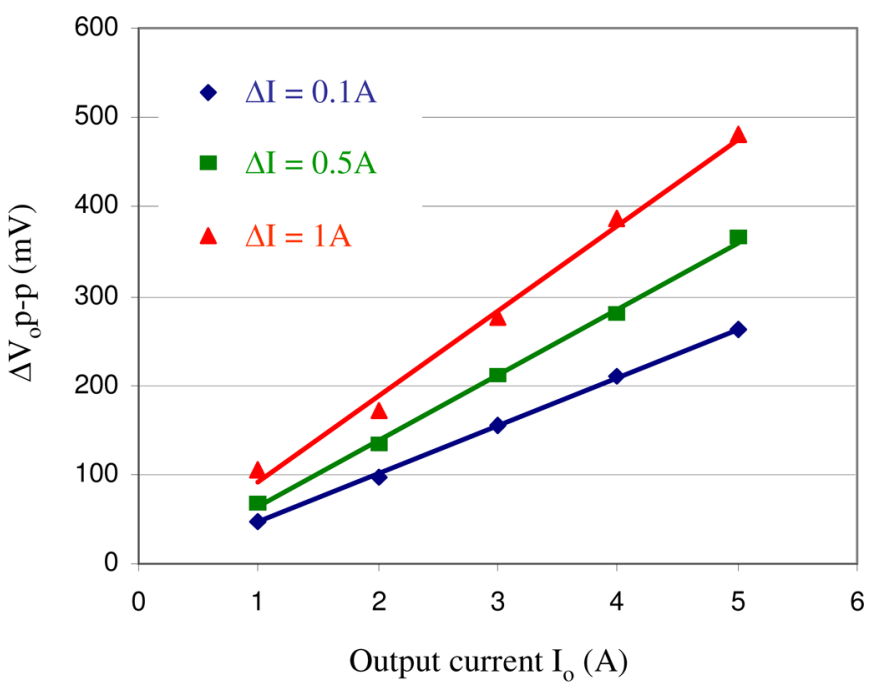

(b)

Fig. 17. Simulation of $\Delta V_{\text {op-p }}$ versus $R_{a}, I_{o}, \Delta I$ for $T_{a}=25^{\circ} \mathrm{C}$. (a) $\Delta V_{\text {op-p }}$ versus $R_{a}$ and $\Delta I$ for $I_{o}=5 \mathrm{~A}$. (b) $\Delta V_{\mathrm{op}-\mathrm{p}}$ versus $I_{o}$ and $\Delta I$ for $R_{a} \stackrel{=}{=}$ $19 \mathrm{~m} \Omega$.

We have remarked that $\Delta V_{\text {op-p }}$ is a function of the output current $I_{o}$, the peak current $\Delta I$, the resistance $R_{a}$, and the capacitor impedance $\overline{Z_{c}}$, which depends on the ambient temperature $T_{a}$.

Then, the voltage $\Delta V_{\text {op-p }}$ can be written as

$$
\Delta V_{\text {of }}=h^{\prime}\left(T_{a}, R_{a}, \Delta I, I_{o}\right) .
$$

We emphasize that the $h^{\prime}$ function cannot be written formally because of the irregularity of the capacitor current and $\delta V_{o}$ voltage versus frequency, but in any way, it can be obtained for discrete points, and stored in a database and then used in the online processing of the resistance $R_{a}$.

In Fig. 17, we represent $\Delta V_{\text {op-p }}$ versus resistance $R_{a}$ and current $I_{o}$ for different current bands $\Delta I$ for an ambient temperature fixed at $T_{a}=25^{\circ} \mathrm{C}$.

We applied to the PFC controlled by the hysteresis technique the same variable load state at time $t=2 \mathrm{~s}$ from $I_{o}=1 \mathrm{~A}$ to $I_{o}=5$ A. Fig. 18 shows that $\delta V_{o}$ is not affected by the 


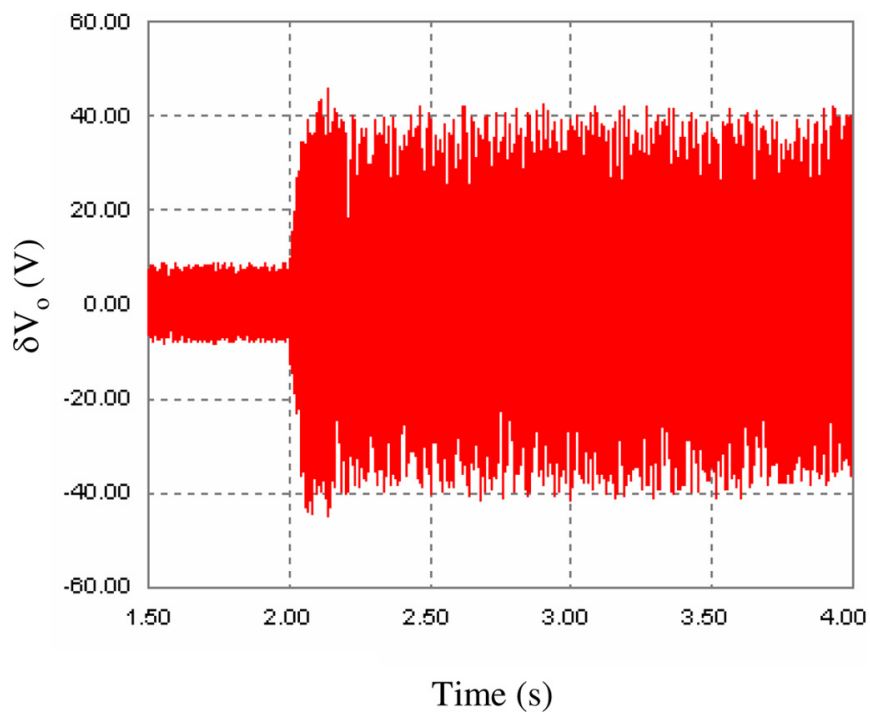

Fig. 18. Simulation of $\delta V_{o}$ versus time for a variable $I_{o}$ from 1 to $5 \mathrm{~A}$.

low-frequency transient voltage that appears in Fig. 13. This means that the monitoring of its amplitude $\Delta V_{\text {op-p }}$ is very interesting since it avoids faulty alarms during the online processing of the resistance $R_{a}$.

\section{Online Prediction of the Electrolytic Capacitor Fault}

We have already demonstrated that the output voltage ripple in a PFC increases with respect to the resistance $R_{a}$ in both PWM and hyteresis control methods. The $R_{a}$ increase versus ageing time $t$ and temperature $T$ is the best indicator of capacitor fault [14]. To determine $R_{a}$ and the time before the capacitor failure, we must first determine at time $t=0$ (for sound capacitors) the parameters $R_{a}, R_{b}, R_{c}, C$, and $L$ of the capacitor electrical model (see Fig. 4) by the use of GA for different ambient temperatures. The result of identification according to the temperature $T$ can be resumed as

$$
R_{a}(T)=a_{1}+a_{2} \exp \left(-\frac{T}{a_{3}}\right)
$$

where $a_{i}$ are coefficient functions of the component.

This expression gives us the $R_{a}^{\circ}$ value for a sound capacitor at any temperature $T$.

Second, the function $R_{a}(t)$ given by (32) is deduced from accelerated ageing tests. So, the coefficients $d_{1}, d_{2}$, and $d_{3}$ are determined.

Third, using software simulation, the functions $h$ and $h^{\prime}$ of respective equations (37) and (38) are determined for different values of $T_{a}, R_{a}, I_{o}$, and $F_{s}(\mathrm{PWM})$ or $\Delta I$ (current-controlled hysteresis). Then, we make a reference system for $\Delta V_{\text {of }}$ and $\Delta V_{\text {op-p }}$.

At any functioning time $t$, for PWM, we measure online $\Delta V_{\text {of }}, I_{o}$, and the case temperature $T_{c}$; for hysteresis control, we also measure online $\Delta V_{\text {op-p }}, I_{o}$, and $T_{c}$. The PFC user will fix the switching frequency $F_{s}$ or the peak-current variation $\Delta I$ as well as the limit allowed for the output voltage ripple $\left(\Delta V_{\text {of }}^{l}\right.$ or $\left.\Delta V_{\text {op-p }}^{l}\right)$.

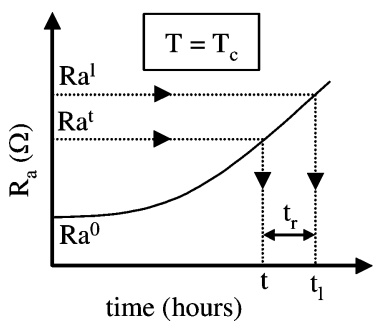

Fig. 19. Computation of the remaining time $t_{r}$ before failure using the law $R_{a}=f(t, T)$ at $T=T_{c}$

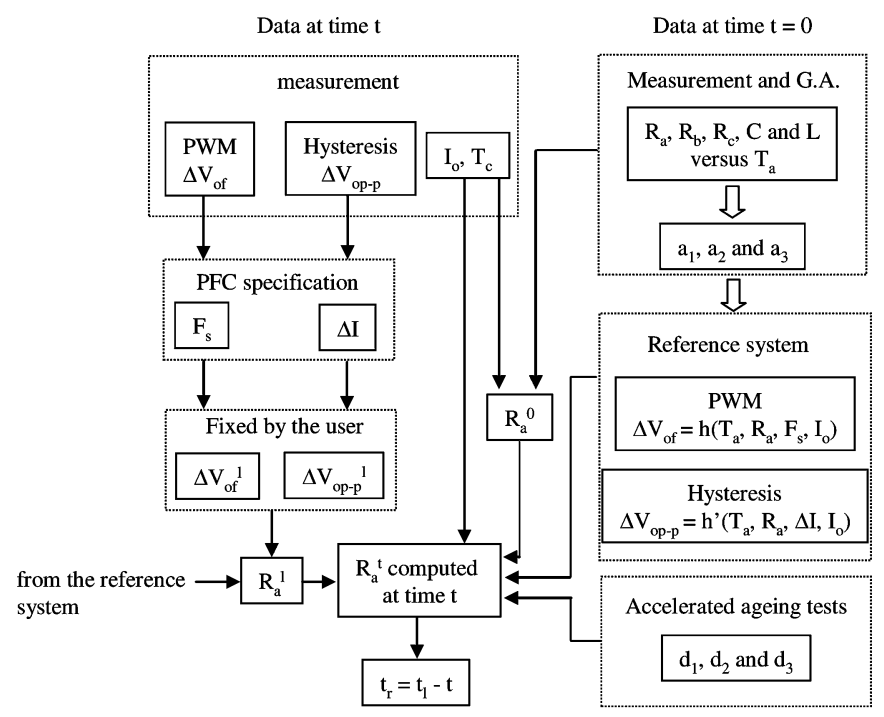

Fig. 20. Block diagram of the capacitor failure prediction.

By using the reference system for each control case, we can deduce the limit value allowed for $R_{a}$ denoted by $R_{a}^{l}$ and compute online at time $t$ the $R_{a}$ value termed $R_{a}^{t}$. Finally, the remaining time to failure $t_{r}$ is calculated, as shown in Fig. 19.

The block diagram illustrated by Fig. 20 summarizes the method used to predict electrolytic capacitor failure.

\section{CONCLUSION}

First, a new power loss estimation approach of electrolytic capacitors is described. By taking into account a new electrical model of the capacitor with parameters tuned through the use of GA, this approach is more efficient and accurate that those already used. Second, the identified capacitor model is introduced into a boost-type PFC circuit controlled by PWM and currentcontrolled hysteresis modulation. Despite of the simplicity of hysteresis control implementation, PWM presents lower power dissipation in the capacitor.

Third, we focused our analysis on the fault detection of the electrolytic capacitor. We found that the series resistance $R_{a}$ of the capacitor new model is the best fault signature of the latter. In fact, the output voltage ripple rises with respect to $R_{a}$, and this is why it is monitored to predict the failure of electrolytic capacitors. We proposed a new method of capacitor failure prediction based on the use of a reference system and real-time output voltage ripple measurement. This new method 
avoids faulty alarms due to load variations. At any functioning time $t$, for PWM or hysteresis control, PFC user can determine online the remaining time before capacitor failure.

\section{REFERENCES}

[1] A. Lahyani, P. Venet, G. Grellet, and P. J. Viverge, "Failure prediction of electrolytic capacitors during operation of a switch mode power supply," IEEE Trans. Power Electron., vol. 13, no. 6, pp. 1199-1207, Nov. 1998.

[2] A. M. Imam, D. M. Divan, R. G. Harley, and T. G. Habetler, "Real-time condition monitoring of the electrolytic capacitors for power electronics applications," in Proc. IEEE Appl. Power Electron. Conf. Expo., 2007, pp. 1057-1061.

[3] Y.-M. Chen, H.-C. Wu, M.-W. Chou, and K.-Y. Lee, "Online failure prediction of the electrolytic capacitor for LC filter of switching-mode power converters," IEEE Trans. Ind. Electron., vol. 55, no. 1, pp. 400-406, Jan. 2008.

[4] M. L. Gasperi, "Life prediction method for aluminium electrolytic capacitors," in Proc. IEEE IAS Conf., 1996, pp. 1347-1351.

[5] K. Harada, A. Katsuki, and M. Fujiwara, "Use of ESR for deterioration diagnosis of electrolytic capacitors," IEEE Trans. Power Electron., vol. 8, no. 4, pp. 355-361, Oct. 1993.

[6] A. Lahyani, P. Venet, and G. Grellet, "Design of processing system for state diagnosis of electrolytic capacitors," EPE J., vol. 11, no. 1, pp. 1924, Feb. 2001.

[7] B. Alvsten, "Electrolytic capacitors, theory and application," presented at the RIFA Electrolytic Capacitors, Sweden, 1995.

[8] A. Lahyani, A. Braham, and A. Bouhachem, "Power loss estimation of electrolytic capacitor using genetic algorithm," in Proc. Int. Telecommun. Energy Conf. (INTELEC) 2007, Rome, Italy, pp. 875-879.

[9] T. Kurachi, M. Shoyama, and T. Ninomiya, "Analysis of ripple current of an electrolytic capacitor in power factor controller," in Proc. Int. Conf. Power Electron. Drive Syst., 1995, vol. 1, pp. 48-53.

[10] F. Perisse, P. Venet, J. M. Retif, and G. Rojat, "Parameters determination of electrolytic capacitor model by genetic algorithm," presented at the CARTS Europe, Nice, France, Oct. 2002.

[11] E. Aeloiza, J. H. Kim, P. Enjeti, and P. Ruminot, "Real time method to estimate electrolytic capacitor condition in PWM adjustable speed drives and uninterruptible power supplies," in Proc. IEEE Power Electron. Spec. Conf., 2005, pp. 2867-2872.

[12] D. Goldberg, Genetic Algorithm in Searching Optimisation and Machine Learning. Reading, MA: Addison-Wesly, 1989.

[13] J. H. Holland, Adaptation In Natural And Artificial Systems. Cambridge, MA: MIT Press, 1992.

[14] K. Abdennadher, P. Venet, G. Rojat, J. M. Retif, and C. Rosset, "A real time predictive maintenance system of aluminium electrolytic capacitors used in uninterrupted power supplies," in Proc. IEEE Ind. Appl. Soc. Annu. Meeting, Edmonton, AB, Canada, 2008, pp. 1-6.

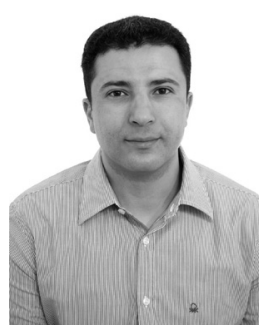

Ahmed Braham was born in Tunis, Tunisia, on August 10, 1972. He received the Engineering degree in electrical engineering from Tunis Engineers National School, Tunis, Tunisia, in 1993, the Engineering degree of the special section in advanced power electronics from the Higher Educational College of Electricity, Electronics, Computer Science-Data Processing and Hydraulics of Toulouse, Toulouse, France, in 1994, the Postgraduate degree in 1994 and the Ph.D. degree in electrical engineering, respectively from the National Polytechnic Institute of Toulouse, Toulouse, France, in 1997.

Since 1998, he has been an Assistant Professor at Tunis Applied Sciences and Technology National Institute (INSAT), Tunis. His current research interests include power electronics, especially the diagnosis of static converters and three-phase induction motors, and the design of real-time systems.

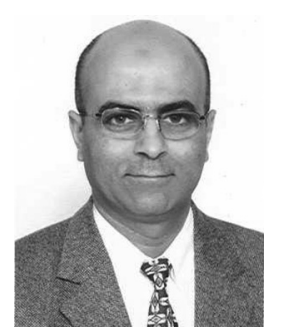

Amine Lahyani was born in Sfax, Tunisia, on October 30, 1970. He received the Engineering and Postgraduate degrees in electrical engineering from the National Polytechnic Institute of Grenoble (INPG), Grenoble, France, in 1994, and the Ph.D. degree in electrical engineering from Electrical Engineering Laboratory (AMPERE), Claude Bernard University Lyon I, Lyon, France, in 1998.

Since 1998, he has been an Assistant Professor at Tunis Applied Sciences and Technology National Institute, Tunis, Tunisia. His current research interests include power electronics, especially passive components and safety functioning of static converters.

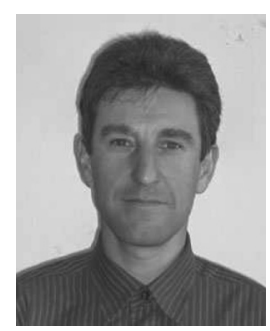

Pascal Venet was born in Aix-Les-Bains, France, on March 16, 1965. He received the Ph.D. degree in electrical engineering from the University Lyon 1, Lyon, France, in 1993.

Since 1995, he has been a Professor at the University Lyon 1, where he developed his research activity in the Electrical Engineering Laboratory (AMPERE). His current research interests include static converters fault diagnostics and ageing of components such as electrolytic capacitors, supercapacitors, and batteries.

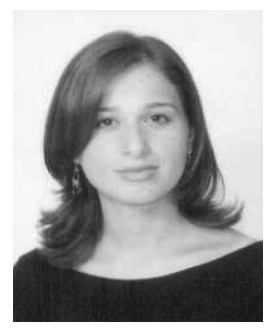

Nejla Rejeb was born in Mahdia, Tunisia, on October 9, 1981. She received the Engineering Diploma and the Master's degree in industrial computer science and automation from Tunis Applied Sciences and Technology National Institute, Tunis, Tunisia, in 2007 and 2009, respectively.

She is currently with the Unité de recherche Matériaux, Mesures et Applications (MMA), Tunis Applied Sciences and Technology National Institute, Tunis. Her current research interests include fault diagnosis of static converters. 